\title{
Optimasi Penentuan Posisi Evolved Node B Long Term Evolution pada BTS GSM yang Terpasang Menggunakan Fuzzy Evolutionary Algorithm
}

\section{Optimization of Determination of Evolved Node B Long Term Evolution Position at Existing GSM BTS Using Fuzzy Evolutionary Algorithm}

\author{
Anisari Mei Prihatini ${ }^{*}$, Sholeh Hadi P., dan Rahmadwati
}

Jurusan Elektro Fakultas Teknik, Universitas Brawijaya

Jalan M.T Haryono 167, Malang 65145, Indonesia

\begin{abstract}
Abstrak
LTE (Long Term Evolution) atau yang disebut dengan teknologi 4G merupakan suatu teknologi telekomunikasi bergerak yang dikeluarkan oleh 3GPP Release 8 dan merupakan pengembangan dari HSDPA. Untuk membangun sebuah jaringan LTE di suatu daerah, penyelenggara jasa jaringan telekomunikasi harus membangun infrastuktur sistem komunikasi seluler baru. Salah satu aspek yang sangat berperan dalam pembangunan infrastruktur adalah pembangunan Evolved NodeB (ENodeB). Meningkatnya pembangunan menara ENodeB baru memberikan dampak pada faktor keamanan lingkungan, kesehatan masyarakat dan estetika lingkungan. Pada penelitian ini akan dilakukan optimasi untuk menempatkan ENodeB pada BTS yang telah terpasang menggunakan metode Fuzzy Evolutionary Algorithm (FEA). Hasil yang didapatkan adalah penempatan 58 ENodeB pada BTS yang telah terpasang. Performansi penempatan ENodeB menggunakan Fuzzy Evolutionary Algorithm sebesar 84\%. Fuzzy Evolutionary Algorithm mencapai kestabilan pada nilai 84 dengan nilai optimalitas sebesar 100 dan trafik sebesar 68 .
\end{abstract}

Kata kunci: ENodeB, LTE, Fuzzy Evolutionary Algorithm.

\section{Abstract}

LTE (Long Term Evolution) or so-called $4 G$ technology is a mobile telecommunication technology issued by 3GPP Release 8 and it is a development of HSDPA. To build an LTE network, the telecommunications network service provider must build a new mobile communication system infrastructure. One aspect that was important to build infrastructure is Evolved NodeB (ENodeB). The increasing number of ENodeB will impact on the safety factor of the environment, public health and environmental aesthetics. This research will be optimized ENodeB position on existing base stations using Fuzzy Evolutionary Algorithm (FEA) method. The obtained results are the placement of 58 ENodeB on existing base stations. The performance ENodeB positioning using FEA is $84 \%$. The stable condition is reach on 84 , that value consist of two factors, the optimality factor is 100 and traffic factor is 68.

Keywords: ENodeB, LTE, Fuzzy Evolutionary Algorithm.

\section{Pendahuluan}

Kebutuhan pelanggan jaringan telekomunikasi untuk penggunaan mobile data dan aplikasi multimedia meningkat setiap tahunnya. Pada tahun 2013-2018 diprediksi penggunaan trafik data global per bulan akan melebihi 15 Exabytes yang mana mengindikasikan pertumbuhan sebesar $1000 \%$ dalam kurun waktu 5 tahun [1]. Di Indonesia diperkirakan jumlah pelanggan data mencapai 270 juta pengguna dalam kurun waktu 34 tahun mendatang [2]. Oleh sebab itu, dibutuhkan peningkatan kecepatan penambahan kapasitas jaringan. Third Generation Partnership Project (3GPP)

* Corresponding Author.

Email: anisarimei@gmail.com

Received: November 20, 2015; Revised: November 27, 2015

Accepted: December 20, 2015

Published: December 30, 2015

(C) 2015 PPET - LIPI

doi : $10.14203 /$ jet.v15.39-44 mengembangkan teknologi yang dapat meningkatkan performa jaringan mobile, salah satunya adalah Long Term Evolution (LTE). LTE merupakan kelanjutan dari teknologi jaringan GSM/EDGE and UMTS/HSxPA tetapi memiliki kemampuan untuk mendukung bandwidth yang lebih lebar dari 5MHz. LTE dirancang untuk meningkatkan throughput dan kapasitas base station, mengurangi latensi, dan full mobility [3].

Munculnya teknologi baru dan peningkatan jumlah pelanggan seluler akan membuat penyelenggara jasa jaringan telekomunikasi membangun infrastuktur sistem komunikasi seluler. Salah satu aspek yang sangat berperan dalam pembangunan infrastruktur adalah penempatan posisi Evolved Node B (ENodeB). ENodeB memiliki fungsi seperti perangkat Base Transmitter Station (BTS) yaitu sebagai pengirim dan penerima sinyal. Jika suatu daerah yang memiliki kluster pelanggan dengan kepadatan dan tingkat layanan trafik yang cukup, maka di tempat tersebut akan ada 
pembangunan menara telekomunikasi. Selanjutnya bila dalam kurun waktu tertentu terdapat perkembangan atau peningkatan pelanggan yang signifikan, akan ada penambahan pembangunan menara baru, begitu seterusnya. Meningkatnya pembangunan menara baru akan memberikan dampak pada faktor keamanan lingkungan, kesehatan masyarakat dan estetika lingkungan [4]. Salah satu solusi yang dapat mengurangi hal tersebut adalah menempatkan ENodeB pada BTS yang telah terpasang.

Penelitian ini menggunakan Fuzzy Evolutionary Algorithm (FEA) yang merupakan konsep gabungan dua buah model soft computing yaitu algoritma genetika dan logika fuzzy [5]. Dalam algoritma genetika, pengguna harus mendefinisikan beberapa parameter pada awal running agar proses dapat berjalan dengan baik. Terdapat tiga parameter penting dalam algoritma genetika yaitu ukuran populasi, probabilitas crossover $(\mathrm{Pc})$, dan probabilitas mutasi $(\mathrm{Pm})[6]$. Ketiga parameter ini harus didefinisikan secara hati-hati agar tidak terjadi konvergensi dini sehingga mengakibatkan solusi yang dihasilkan bukanlah solusi yang optimum. Hal tersebut dapat terjadi diakibatkan karena nilai Pc dan Pm bernilai random (acak). Untuk mengatasi masalah tersebut, diperlukan metode tambahan yang mampu mengatasi kelemahan pada algoritma genetika yaitu dengan menambahkan konsep Fuzzy untuk mengatur nilai Pc dan Pm selama proses evolusi [7].

Terdapat beberapa penelitian yang berkaitan dengan posisi penentuan base station antara lain penelitian yang dilakukan oleh Pancawati Dessy yang menggunakan algoritma genetika untuk optimasi penempatan Node B UMTS900 pada BTS yang ada (existing). Hasil penelitian menyebutkan performansi penempatan Node $B$ ditentukan oleh daya cakup wilayah (coverage area) yang dihasilkan yaitu sebesar $35 \%$ dan tingkat layanan trafiknya sebesar $61 \%$. Tingkat optimasi masih dapat dikatakan rendah [8].

Muhammad Fachrie dkk, menggunakan Fuzzy Evolutionary Algorithm untuk memperhitungkan penempatan Base Transceiver Station, dari hasil penelitian didapatkan luas area yang berhasil ter-cover sebesar 90,57\% dengan tingkat layanan trafik sebesar $82,84 \%$. Hasil perhitungan menggunakan FEA dianggap lebih baik dibandingkan dengan penempatan BTS menggunakan algoritma lainnya [7].

Penelitian ini merupakan pengembangan dari penelitian yang telah dilakukan sebelumnya. Penelitian ini dimaksudkan untuk memperoleh posisi optimum dalam penempatan ENodeB LTE pada BTS Global System for Mobile (GSM) yang terpasang menggunakan metode Fuzzy Evolutionary Algorithm.

\section{TINJAUAN PUSTAKA}

\section{A. Long Term Evolution (LTE)}

Long Term Evolution LTE adalah sebuah nama yang diberikan pada sebuah projek Third Generation Partnership Project (3GPP) untuk memperbaiki standar mobile phone generasi ketiga (3G). LTE memberikan kemampuan kecepatan transfer data mencapai 100 Mbps pada sisi downlink dan 50 Mbps pada sisi Uplink. LTE juga mampu mendukung semua aplikasi multimedia contohnya voice, data, video maupun IPTV. Selain itu, LTE juga memberikan coverage area dan kapasitas layanan yang lebih besar, mendukung penggunaan multiple-antenna, fleksibel dalam penggunaan bandwidth dan dapat terhubung dan terintegrasi dengan teknologi yang sudah ada [9].

Langkah yang dilakukan untuk perencanaan jaringan LTE antara lain penentuan daerah layanan, estimasi jumlah pelanggan LTE, perhitungan OBQ (Offered Bit Quantity) pelanggan, kapasitas kanal, jumlah sel, dan radio link budget.

\section{1) Identifikasi Daerah Layanan}

Berdasarkan kepadatan dan tingkat aktivitas penduduk, wilayah dapat dibagi menjadi tiga jenis yaitu wilayah rural, urban dan suburban. Wilayah urban adalah wilayah yang memiliki tingkat kepadatan dan aktivitas manusia yang lebih tinggi daripada daerah sekitarnya, misalnya wilayah perkotaan, pusat pemerintahan, pusat perbelanjaan dan perkantoran. Wilayah suburban adalah wilayah yang tingkat kepadatan penduduknya lebih rendah daripada daerah urban. Sedangkan wilayah rural adalah wilayah dengan tingkat kepadatan penduduk paling rendah.

\section{2) Perhitungan Jumlah Pelanggan}

Estimasi jumlah pelanggan dapat dihitung menggunakan persamaan berikut [8],

$$
U_{n}=U_{o}\left(1+f_{p}\right)^{n}
$$

di mana

$$
\begin{array}{ll}
U_{n} & \text { : Jumlah pelangganpada tahun ke-n, } \\
U_{o} & \begin{array}{l}
\text { : Jumlah pelanggan pada tahun } \\
\text { perencanaan, }
\end{array} \\
& \text { : faktor pertumbuhan, } \\
f_{p} & \text { : Jumlah tahun prediksi. }
\end{array}
$$

\section{3) Perhitungan Offered Bit Quantity (OBQ)}

OBQ adalah total bit troughput per $\mathrm{km}^{2}$ pada jam sibuk. Untuk menghitung OBQ $\left(\mathrm{kbps} / \mathrm{km}^{2}\right)$ digunakan persamaan berikut [8],

$$
O B Q=\sigma \times p \times d \times B H C A \times B W
$$

di mana,

$$
\begin{array}{ll}
O B Q & \begin{array}{l}
\text { Offered Bit Quantity }\left(\mathrm{kbps} / \mathrm{km}^{2}\right), \\
\text { : kepadatan pelanggan suatu daerah } \\
\\
\left(\text { user } / \mathrm{km}^{2}\right),
\end{array} \\
p & \begin{array}{l}
\text { : penetrasi pengguna tiap layanan }(\%), \\
\text { : durasi panggilan efektif }(\mathrm{sec}),
\end{array} \\
d & : \text { Busy Hour Call Attempt }(\mathrm{call} / \mathrm{hour}), \\
B H C A & : \text { Net User Bit Rate }(\mathrm{kbps}) .
\end{array}
$$

\section{4) Perhitungan Kapasitas Kanal}

Kapasitas suatu kanal diukur dari jumlah bit sistem yang dapat dikirim per Hertz dari bandwidth tiap detik (bps/Hz). Untuk menghitung kapasitas suatu kanal dapat menggunakan persamaan berikut:

$$
N_{s e l}=\frac{w / p}{[E b / N o]} \frac{\beta}{\alpha[1+f]}
$$

di mana:

$\mathrm{R} \quad$ : Data rate (Kbps), 
Eb/No : Energi bit per noise $(\mathrm{dB})$,

W : Bandwidth(Mbps),

$\alpha \quad$ : Activity factor,

$\beta \quad$ : Gain sektorisasi antenna,

$f \quad$ : Faktor interferensi.

5) Perhitungan Jumlah Sel

Jumlah sel dapat diperoleh dari hasil bagi antara luas daerah perencanaan dengan luas cakupan suatu sel, sehingga diperoleh persamaan rumus sebagai berikut [8],

$$
\text { Jumlah Sel }=\frac{\text { Luas Area Perencanaan }}{\text { Luas Cakupan Sel }}
$$

\section{6) Perhitungan Radio Link Budget}

Perhitungan radio link budget digunakan untuk memperkirakan nilai maksimum pelemahan sinyal atau Maximum Allowable Path Loss (MAPL) antara antenna mobile dan antenna base station.

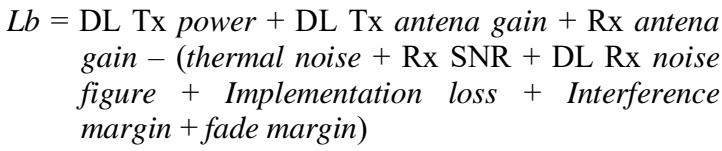

\section{B. Evolutionary Algorithm (EAs)}

EAs merupakan algoritma-algoritma optimasi yang berbasis evolusi biologi yang ada di dunia nyata. Dalam teori evolusi, suatu populasi terdiri atas sejumlah individu hidup di suatu daerah yang memiliki sumber daya terbatas. Dengan demikian, kompetisi antarindividu untuk memperebutkan sumber daya terbatas tersebut menyebabkan individu-individu dengan tingkat adaptasi yang lebih tinggi akan bertahan hidup dan yang lain akan musnah. Proses alamiah inilah yang diadopsi oleh EAs untuk menyelasaikan masalah-masalah komputasi [6].

\section{Logika Fuzzy}

Logika fuzzy adalah sistem berbasis aturan yang di dalamnya terdapat himpunan aturan fuzzy yang mempresentasikan mekanisme pengambilan keputusan. Aturan yang dibuat digunakan untuk memetakan variabel input ke variabel output dengan pernyataan If Then. Proses ini akan menggunakan data tertentu (crisp) kemudian mengubahnya menjadi bentuk fungsi keanggotaan melalui proses fuzzifikasi. Lalu dengan aturan fuzzy, inference engine yang akan menentukan hasil keluaran fuzzy. Setelah itu hasil ini akan diubah kembali menjadi bentuk numerik melalui proses defuzzifikasi [10].

\section{Metode Penelitian}

Tahapan ini berisi kerangka solusi masalah yang dilakukan untuk mendapatkan posisi ENodeB yang optimal, antara lain perencanaan kapasitas, perencanaan cakupan dan optimasi penempatan posisi EnodeB.

\section{A. Perencanaan Kapasitas}

Perencanaan berdasarkan kapasitas yang terdiri dari beberapa aspek di antaranya identifikasi daerah layanan, estimasi jumlah pelanggan, perhitungan kebutuhan trafik pelanggan dan perhitungan kapasitas sel.

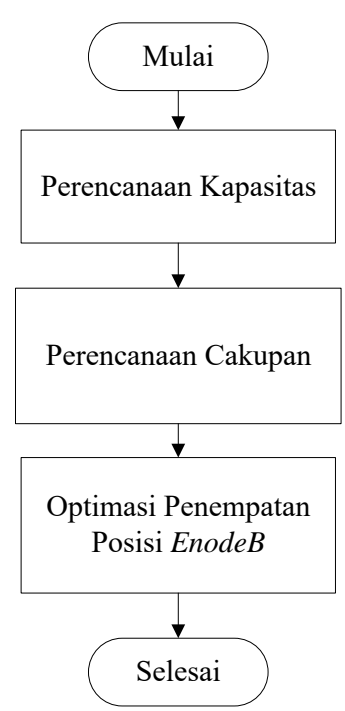

Gambar 1. Tahapan Optimasi Penempatan ENodeB LTE.

\section{B. Perencanaan Cakupan}

Perencanaan berdasarkan cakupan, yang meliputi beberapa aspek antara lain perhitungan radio link budget, perhitungan radius sel dan jumlah sel yang dibutuhkan.

\section{Optimasi Penempatan Posisi ENodeB}

Penempatan posisi ENodeB pada BTS yang telah terpasang dipengaruhi oleh faktor optimalitas dan trafik.

\section{Hasil dan Pembahasan}

\section{A. Identifikasi Daerah Layanan}

Objek perencanaan penelitian ini berada di Kota Surabaya. Kota Surabaya terletak pada posisi $7,9^{\circ}-7,21^{\circ}$ Lintang Selatan, $112,36^{\circ}-112,54^{\circ}$ Bujur Timur. Luas Wilayah Kota Surabaya sebesar $316,36 \mathrm{~km}^{2}$ yang terbagi dalam 31 kecamatan. Klasifikasi pembagian daerah Kota Surabaya termasuk dalam kategori daerah urban karena Surabaya termasuk kota besar yang mana terdapat pusat pemerintahan Provinsi Jawa Timur, daerah bisnis dan perkantoran dengan banyak gedung pencakar langit (minimal 20 meter) dan kepadatan penduduk lebih dari $19.200 / \mathrm{Km}^{2}$.

\section{B. Estimasi Jumlah Pelanggan LTE}

Estimasi jumlah pelanggan LTE akan dilakukan dalam kurun waktu 5 tahun kedepan terhitung dari tahun 2015-2020. Data yang digunakan dalam perhitungan estimasi jumlah penduduk yaitu data penduduk Kota Surabaya tahun 2010 yang didapatkan dari Badan Pusat Statistik Surabaya [11]. Dengan tingkat penetrasi seluler sebesar $85 \%$ dari jumlah penduduk dan tingkat penetrasi provider $\mathrm{X}$ sebesar $21,7 \%$, maka didapatkan hasil estimasi jumlah pelanggan seperti yang terlihat pada Gambar 2.

\section{Perhitungan Offered Bit Quantity (OBQ)}

Tingkat kepadatan pelanggan LTE wilayah urban sebesar 2250 user $/ \mathrm{km}^{2}$ dengan distribusi pelanggan diasumsikan $50 \%$ building, 30\% pedestrian dan $20 \%$ vehicular [8], sehingga didapatkan hasil perhitungan OBQ seperti yang tertera pada Tabel 1 . 


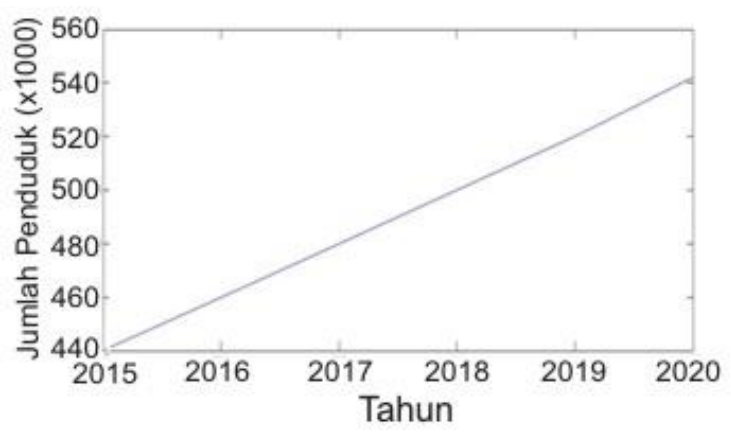

Gambar 2. Estimasi Jumlah Pelanggan LTE.

TABEL 1

PERHITUNGAN OFFERED BIT QUANTITY (OBQ)

\begin{tabular}{|c|c|c|}
\hline No. & Tingkat Pergerakan User & OBQ $\left(\mathrm{kbps} / \mathrm{km}^{2}\right)$ \\
\hline 1 & Building & 831 \\
\hline 2 & Pedestrian & 218,88 \\
\hline 3 & Vehicular & 46,152 \\
\hline \multicolumn{2}{|r|}{ TOTAL } & 1096,032 \\
\hline
\end{tabular}

\section{Perhitungan Kapasitas Kanal}

Kapasitas kanal dapat dihitung menggunakan Persamaan 3, dengan besarnya:

Bit rate $(\mathrm{R}): 1000 \mathrm{Kbps}$,

$\mathrm{Eb} / \mathrm{No} \quad: 1 \mathrm{~dB}$,

Bandwidth : $5 \mathrm{MHz}$

$\begin{array}{ll}\alpha & : 1, \\ \beta & : 2,4, \\ f & : 0,6 .\end{array}$

Sehingga diperoleh kapasitas kanal adalah 5,95758 $\mathrm{kanal} / \mathrm{sel}$ atau $5957,58 \mathrm{Kbps} / \mathrm{sel}$.

\section{E. Perhitungan Jumlah ENodeB}

Luas area sebuah ENodeB dengan asumsi masingmasing sektor pada BTS sebanyak 3 sektor didapatkan $5,4355 \mathrm{~km}^{2}$. Setelah ditemukan luas tiap sel maka dengan menggunakan persamaan 4 didapatkan jumlah ENodeB sebanyak 58 sel.

\section{F. Simulasi Fuzzy Evolutionary Algorithm}

Langkah-langkah yang dilakukan untuk simulasi FEA antara lain:

\section{1) Menghitung Trafik BTS}

Suatu ENodeB dalam perencanaan ini memiliki radius sel $1,0719 \mathrm{~km}$ dan untuk mengetahui besarnya trafik tiap ENodeB caranya adalah dengan menghitung berapa banyak penduduk yang berhasil tercover oleh suatu ENodeB. Setelah dihitung, nilai trafik dari BTS-1 hingga BTS-85 adalah sebagai berikut:

$354,332,375,321,302,372,421,386,341,338,416,451,583$ ,469,479,486,537,318,326,315,379,422,547,532,476,87 $6,763,532,412,634,498,525,534,503,421,365,752,47447$ $6,589,465,532,456,496,542,587,385,583,492,582,427,4$ $93,693,496,572,372,594,573,629,535,592,751,484,641$, $304,496,385,659,523,417,739,673,538,486,355,470,507$ ,459

\section{2) Perancangan FEA} berikut:

Perancangan FEA menggunakan ketentuan sebagai

a) Jumlah generasi sebanyak 50,

b) Populasi terdiri dari 10 individu, c) Individu memiliki 85 gen yang merupakan jumlah BTS yang telah terpasang,

d) Nilai fitness ditentukan oleh 2 faktor yaitu optimalitas dan trafik. Nilai fitness memiliki rentang nilai $0-100$.

\section{3) Membangkitkan Individu}

Suatu individu memiliki 85 gen dan dibangkitkan secara acak. Setiap gen direpresentasikan dengan bilangan biner (1 atau 0). Apabila gen bernilai 1, artinya gen tersebut merupakan kandidat yang akan dipasang ENodeB dan sebaliknya. Contoh individu: 010010010001011101111100100000001011011010111 0101111100001101001111010110111110110101

\section{4) Inisialisasi Populasi}

Inisialisasi populasi dilakukan untuk membangkitkan individu sebanyak ukuran populasi. Populasi terbentuk dari 10 individu. Berikut ini merupakan salah satu contoh individu pada generasi ke0 .

(0) 01001001000101110111110010000000101101101 01110101111100001101001111010110111110110

$101(\mathrm{o}=81, \mathrm{t}=52, \mathrm{f}=66)$

Individu tersebut memiliki nilai optimalitas sebesar 81 , trafik sebesar 52 dan nilai fitness sebesar 66 .

\section{5) Seleksi Orang Tua}

Proses ini akan memilih individu terbaik berdasarkan perhitungan jumlah nilai fungsi fitness. Individu dengan nilai fitness tertinggi akan tetap dipertahankan untuk dijadikan orang tua. Individu tersebut dipilih menggunakan metode seleksi busur roda roulette.Pasangan orang tua yang terbentuk pada proses roulette antara lain individu 5 -individu 7 , individu 8 individu 1 , individu 5 -individu 5 , individu 7 -individu 4 , individu 0 -individu 3.

\section{6) Perancangan Fuzzy}

Perancangan logika Fuzzy digunakan sebagai perhitungan nilai probabilitas crossover (Pc) dan probabilitas mutasi (Pm). Terdapat dua masukan untuk logika Fuzzy yaitu jumlah generasi (g) dan nilai fitness (f). Jumlah generasi (g) dan nilai fitness masing-masing dapat dilihat pada Gambar 3 dan Gambar 4.

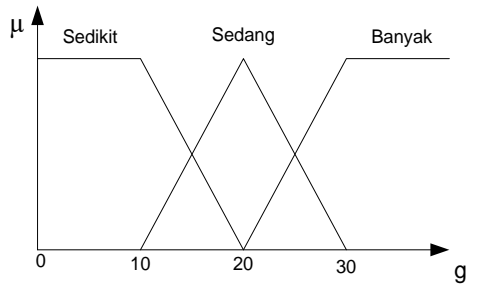

Gambar 3. Fungsi Keanggotaan Jumlah Generasi (g).

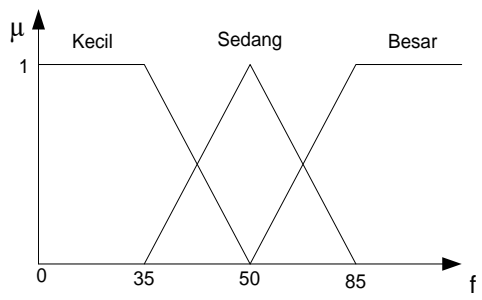

Gambar 4. Fungsi Keanggotaan Nilai Fitness (f). 
Fungsi persentase keanggotaan Pc dan Pm (seperti yang terlihat pada Gambar 5 dan 6) berbentuk singleton. Fungsi output Pc dan Pm masing-masing terdiri dari lima label yaitu SK (Sangat Kecil), K (Kecil), S (Sedang), B (Besar), dan SB (Sangat Besar).

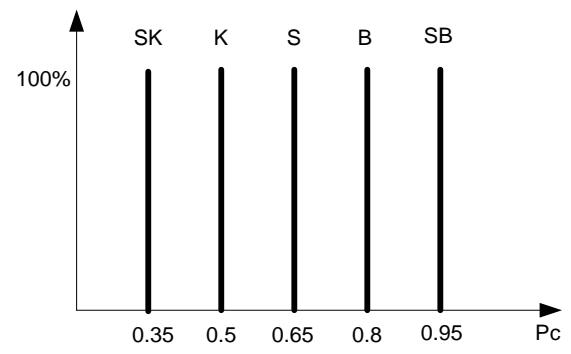

Gambar 5. Fungsi Persentase Keanggotaan Pc.

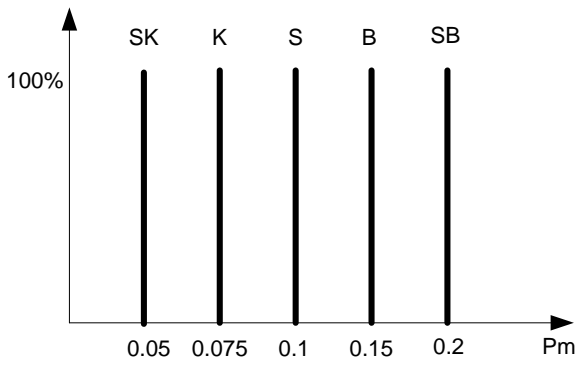

Gambar 6. Fungsi Persentase Keanggotaan Pm.

Setelah masukan diubah ke dalam variabel linguistic, selanjutnya diolah sesuai dengan kaidah aturannya (rule).

TABEL 2

KAIDAH ATURAN LOGIKA FUZZY PC

\begin{tabular}{|c|c|c|c|}
\hline & \multicolumn{3}{|c|}{ Fitness } \\
Generasi & Kecil & Sedang & Besar \\
\hline Sedikit & Sedang (S) & Kecil (K) & Sangat Kecil (SK) \\
\hline Sedang & Besar (B) & Sedang (S) & Kecil (K) \\
\hline Banyak & Sangat Besar (SB) & Besar (B) & Sedang (S) \\
\hline
\end{tabular}

TABEL 3

KAIDAH ATURAN LOGIKA FUZZY PM

\begin{tabular}{|c|c|c|c|}
\hline & \multicolumn{3}{|c|}{ Fitness } \\
Generasi & Kecil & Sedang & Besar \\
\hline Sedikit & Sangat Besar (SB) & Besar (B) & Sedang (S) \\
\hline Sedang & Besar (B) & Sedang (S) & Kecil (K) \\
\hline Banyak & Sedang (SB) & Kecil (K) & Sangat Kecil (SK) \\
\hline
\end{tabular}

Setelah didapatkan aturan yang berlaku selanjutnya dilakukan defuzzifikasi. Defuzzifikasi adalah proses mengubah keluaran Fuzzy menjadi keluaran crips. Hasil defuzzifikasi berupa nilai Pc dan Pm. Metode defuzzifikasi yang digunakan adalah Center of Area (COA).

\section{7) Kawin Silang (Crossover)}

Proses kawin silang merupakan langkah yang dilakukan untuk menghasilkan individu-individu keturunan berdasarkan pasangan individu induk. Proses ini terlebih dahulu memilih sejumlah pasangan individu berdasarkan nilai probabilitas crossover $(\mathrm{Pc})$ yang telah dihitung menggunakan fuzzy, kemudian pasangan individu tersebut disilangkan untuk menghasilkan pasangan individu keturunan. Dalam pengujian, metode kawin silang yang digunakan adalah metode uniform crossover. Jika pola bernilai 1, maka gen kedua induk ditukar, dan sebaliknya, jika pola bernilai 0 maka gen kedua induk tidak ditukar. Gambar 7 merupakan ilustrasi uniform crossover.

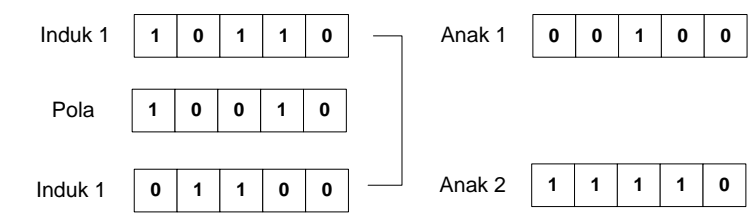

Gambar 7. Ilustrasi Individu yang Mengalami Crossover.

\section{8) Mutasi}

Setelah penerapan proses crossover, semua individu hasil crossover akan mengalami mutasi. Proses ini menggunakan metode uniform mutation, yang mana peluang pengacakan sebesar 50\%. Apabila individu masuk peluang maka individu tersebut melanjutkan proses mutasi, apabila tidak maka individu keluar tanpa proses mutasi. Individu yang masuk peluang mutasi melanjutkan proses mutasi dengan nilai Pm yang dihitung menggunakan logika Fuzzy.

\section{9) Elitisme}

Elitisme adalah proses mengganti individu terjelek setelah proses mutasi dan diganti dengan individu terbaik sebelum proses perkawinan. Pada proses ini, apabila terdapat 2 individu hasil yang nilai fitness-nya paling rendah akan diganti dengan 2 individu yang fitness-nya paling tinggi pada proses roulette.

\section{G. Eksekusi Fuzzy Evolutionary Algorithm}

Setelah dieksekusi, didapatkan nilai fitness dari generasi ke-0 sampai generasi ke- 16 masih belum stabil. Nilai fitness telah stabil selama 10 generasi yaitu generasi ke-17 hingga generasi ke-26 sehingga algoritma bisa dihentikan. Fitness mencapai kestabilan di angka 84 dengan nilai optimalitas sebesar 100 dan trafik sebesar 68. Nilai optimalitas 100 artinya jumlah ENodeB yang akan dipasang sesuai dengan perencanaan yaitu berjumlah 58 ENodeB. Nilai trafik 68 artinya pelanggan yang dapat dilayani adalah $68 \%$ dari total pelanggan LTE di Surabaya. Nilai trafik belum mencapai nilai maksimal karena ENodeB yang lebih banyak terpasang di daerah tengah kota. Hal tersebut dapat terjadi karena trafik tengah kota lebih tinggi daripada daerah pinggir Kota Surabaya.

Pada Gambar 8 terlihat bahwa persebaran ENodeB hampir merata dan terdapat beberapa ENodeB yang

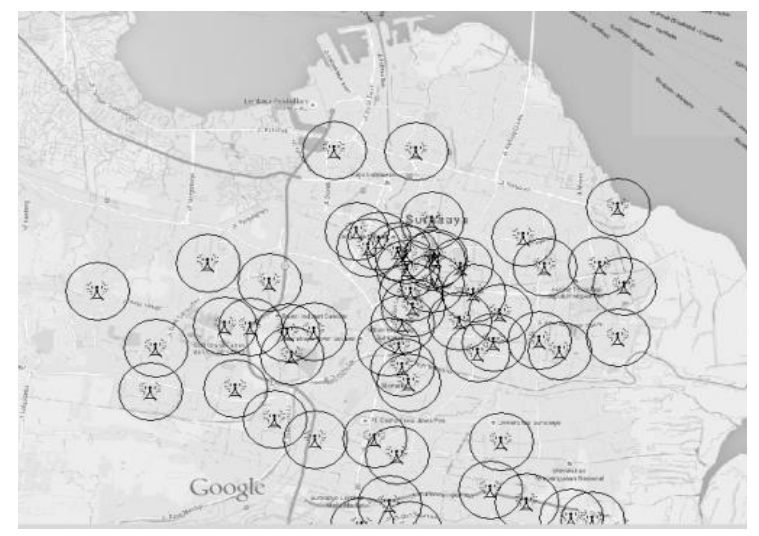

Gambar 8. Hasil Tampilan ENodeB LTE di Surabaya. 
ditempatkan di tengah kota. Hal ini disebabkan oleh trafik di wilayah tengah kota yang cenderung lebih tinggi daripada daerah lainnya, sehingga perlu dipasang beberapa ENodeB untuk memenuhi kebutuhan trafik di wilayah tersebut. Tingginya trafik di wilayah tengah kota disebabkan oleh padatnya pemukiman penduduk serta terdapat pusat pemerintahan, perkantoran, dan banyaknya tempat hiburan di wilayah tersebut.

\section{KESIMPULAN}

Berdasarkan hasil pembahasan yang telah dilakukan, dapat disimpulkan bahwa jumlah ENodeB yang dibutuhkan sesuai dengan perencanaan LTE di Kota Surabaya sebanyak 58 EnodeB. Dan dari hasil eksekusi FEA, didapatkan nilai fitness mulai stabil pada saat generasi ke 17. Performansi penempatan ENodeB menggunakan Fuzzy Evolutionary Algorithm sebesar $84 \%$. Fitness mencapai kestabilan pada nilai 84 dengan nilai optimalitas 100 dan trafik 68.

\section{Daftar Pustaka}

[1] Cisco, Cisco VNI Global Mobile Data Traffic Forecast (20132018): Cisco, 2014
[2] C. Anestia. (2014). Pelanggan data tiga operator besar naik jadi 123,3 juta pengguna. Indonesia Finance Today. [Online]. Available:

http://assets.ift.co.id/pdf/epaper/file/336/Telko 17 3 14.pdf

[3] M. Ergen, Mobile Broadband Including WiMAX and LTE, Berkeley, CA-USA: Springer, 2009.

[4] Pedoman Pembangunan dan Penggunaan Bersama Menara Telekomunikasi, Peraturan Menteri Komunikasi dan Informatika No. 19/Per/M.Kominfo/03/2009, Jakarta. 2009.

[5] S. Muzid, "Pemanfaatan algoritma fuzzy evolusi untuk menyelesaikan kasus travelling salesman problem", dalam Prosiding Seminar Nasional Aplikasi Teknologi Informasi 2008 (SNATI'08), Juni 2008, hal. C33-C38.

[6] Suyanto, Evolutionary Computation Komputasi Berbasis Evolusi dan Genetika, Bandung, Indonesia: Informatika, 2008.

[7] M. Fachrie, S. Widowati, dan A. T. Hanuranto, "Implementasi fuzzy evolutionary algorithms untuk penentuan posisi BTS", dalam Prosiding Seminar Nasional Aplikasi Teknologi Informasi 2012 (SNATI'12), Juni 2012.

[8] P. D. Aryanti, S. H. Pramono, dan O. Setyowati "Optimasi penempatan node B UMTS900 pada BTS existing menggunakan algoritma genetika”, Jurnal EECCIS, vol. 7, no. 2, hal. 111-118, Desember 2013.

[9] U. K. Usman, G. Prihatmoko, D. K. Hendraningrat, dan S. D. Purwanto, Fundamental Teknologi Seluler LTE, Bandung, Indonesia: Rekayasa Sains, 2012.

[10] J. Yan, Using Fuzzy Logic: Towards Intelligent Systems, New York, USA: Practice Hall, 1994.

[11] Badan Pusat Statistik Kota Surabaya. (2010). [On line]. Available: www.surabaya.go.id. 